\title{
Redo surgery with longitudinal resection for dilated bowel in Hirschsprung disease: an illustrative case series
}

\author{
Daniëlle Roorda, MD ${ }^{1}$ (D) - Tessa J. Surridge ${ }^{2} \cdot$ Ruben G. J. Visschers $^{2}$ (D) - Joep P. M. Derikx ${ }^{1}$ (D) \\ L. W. Ernest van Heurn ${ }^{1}$ (I)
}

Accepted: 10 September 2019/Published online: 19 October 2019

(C) The Author(s) 2019

\begin{abstract}
Purpose Patients with Hirschsprung disease (HD) can have persistent obstructive symptoms after resection of the aganglionic segment. If obstructive symptoms are treated inadequately, this may lead to recurrent faecal stasis and impaction, and may result in severe distension of the bowel. A permanently distended bowel which not responds to conservative treatment may be an indication for redo surgery. The aim of this study is to describe our experiences and the short-term results of a novel technique: longitudinal antimesenteric resection with a longitudinal anastomosis.

Methods We reviewed the medical records of our three patients who underwent longitudinal resection of severe distended bowel. This technique aims to improve defecation by improving faecal passage and is characterized by resection of the antimesenteric side of the distended intestinal segment, followed by plication with a longitudinal anastomosis. In this paper, this novel technique is described in detail, as well as short-term outcomes.

Results All patients had an uneventful recovery after longitudinal antimesenteric resection. During follow-up, the functional outcomes were excellent, with a large improvement of bowel function. All patients were continent for faeces, and treated with low-dose laxatives or occasional preventive irrigation in one patient. There were no more complaints of persistent constipation or soiling.

Conclusion Longitudinal resection is a surgical redo-procedure offering large benefits for patients with Hirschsprung disease with distended bowel after primary surgery.
\end{abstract}

Keywords Hirschsprung disease $\cdot$ Re-operation $\cdot$ Obstructive symptoms $\cdot$ Case report

\section{Introduction}

Hirschsprung disease (HD) is a congenital motility disorder characterized by aganglionosis of the distal colon, for which surgery to resect aganglionic bowel is necessary. Thirty to $50 \%$ of patients experience defecation problems after primary surgical treatment [1,2], of which persistent obstructive problems such as constipation are the most common. Possible causes for persistent obstructive complaints include

Daniëlle Roorda, MD

d.roorda@amsterdamumc.nl

1 Emma Childrens Hospital, Amsterdam UMC, Department of Pediatric Surgery, Amsterdam Gastroenterology and Metabolism, University of Amsterdam and Vrije Universiteit Amsterdam, Meibergdreef 9, 1105 AZ Amsterdam, The Netherlands

2 Department of Pediatric Surgery, Maastricht University Medical Center, Maastricht, The Netherlands anastomotic stricture, residual aganglionosis, mechanical obstruction due to adhesions, sphincter problems and stool holding behaviour [3]. Persistent obstructive defecation problems are primarily treated with conservative measures, including laxatives, rectal irrigation, intrasphincteric botulinum toxin injections or anal dilatation [3]. If obstructive symptoms are treated inadequately, this may lead to recurrent faecal stasis and impaction resulting in progressing and permanent distension of the bowel. Severe bowel distension negatively affects bowel motility, thereby aggravating faecal stasis and increasing the risk of developing Hirschsprung-associated enterocolitis (HAEC), which can be life-threatening $[4,5]$. In these patients with persistent obstructive symptoms and permanently dilated bowel, redo surgery may be indicated [6]. Most often a redo pull-through is performed in order to surgically remove the distended non-motile bowel and restore faecal passage. However, redo surgery is complex and associated with relatively high rates of soiling or faecal incontinence and enterocolitis [7-9]. 
Table 1 Clinical characteristics of patients who underwent longitudinal antimesenteric resection

\begin{tabular}{|c|c|c|c|}
\hline & A & B & $\mathrm{C}$ \\
\hline Sex & Male & Male & Male \\
\hline $\begin{array}{l}\text { Age at primary } \\
\text { pull-through }\end{array}$ & 15 days & 4 months & 14 days \\
\hline $\begin{array}{l}\text { Length initial affected and } \\
\text { 7resected segment }\end{array}$ & Rectosigmoid & Descending colon & Rectosigmoid \\
\hline Previous interventions & $\begin{array}{l}\text { Botulinum toxin injections } \\
\text { (age } 4 \text { years): no } \\
\text { improvement } \\
\text { of obstructive symptoms }\end{array}$ & None & $\begin{array}{l}\text { Anal dilatations and redo pull-through } \\
\text { (age } 8.5 \text { months) because of anastomotic } \\
\text { stricture: initially good improvement of } \\
\text { obstructive symptoms }\end{array}$ \\
\hline $\begin{array}{l}\text { Age at longitudinal } \\
\text { resection }\end{array}$ & 5 years & $\begin{array}{l}\text { i. } 8 \text { years } \\
\text { ii. } 9 \text { years }\end{array}$ & 3 years \\
\hline $\begin{array}{l}\text { Bowel segment treated } \\
\text { with } \\
\text { longitudinal resection }\end{array}$ & $50 \mathrm{~cm}$ descending colon & $\begin{array}{l}\text { First longitudinal resection: } \\
\text { (i) Proximal } 10 \mathrm{~cm} \text { of ascending } \\
\text { colon and (ii) remaining descending } \\
\text { colon until rectal fold } \\
\text { Second longitudinal resection: } \\
100 \mathrm{~cm} \text { of ileum located } 50 \mathrm{~cm} \\
\text { proximal } \\
\text { to the ileocolic valve }\end{array}$ & $\begin{array}{l}27 \mathrm{~cm} \text { of remaining colon after redo } \\
\text { pull-through }\end{array}$ \\
\hline Open vs laparoscopic & Laparoscopic & $\begin{array}{l}\text { i. Open } \\
\text { ii. Open }\end{array}$ & Open \\
\hline Suturing & Stapler & $\begin{array}{l}\text { i. Running handsewn suture } \\
\text { ii. Stapler }\end{array}$ & Running handsewn suture \\
\hline Protection with ostomy & $\begin{array}{l}\text { Temporary transverse } \\
\text { colostomy }\end{array}$ & $\begin{array}{l}\text { i. No ostomy } \\
\text { ii. Temporary ileostomy }\end{array}$ & Temporary ileostomy \\
\hline $\begin{array}{l}\text { Follow-up after } \\
\text { longitudinal } \\
\text { resection }\end{array}$ & 4 years & 4 years & 1.5 years \\
\hline $\begin{array}{l}\text { Complications after } \\
\text { longitudinal resection }\end{array}$ & No & No & No \\
\hline
\end{tabular}

In this paper, we present a case series of three patients successfully treated with an alternative technique for redo surgery in patients with extremely dilated non-motile bowel: resection of the antimesenteric side of the dilated non-motile bowel segment, followed by plication with a longitudinal anastomosis.

\section{Methods}

The medical records of three patients who underwent longitudinal resection and plication were retrospectively reviewed. Data on (1) demographic characteristics of patients (i.e. sex, age at primary pull-through, age at longitudinal resection), (2) disease characteristics and clinical course (i.e. length of the initial affected and resected segment, previous interventions), (3) the procedure of longitudinal resection (i.e. what bowel segment was treated with longitudinal resection, how long this segment was, whether an open or laparoscopic procedure was performed, what type of suturing was used, whether the operation was performed under the protection of an ostomy) and (4) clinical course after longitudinal resection (i.e. occurrence of complications, occurrence of obstructive symptoms, use of laxatives or rectal irrigation, faecal continence and length of follow-up) was extracted from the medical records. Based on this data, a summary of our experiences with the clinical course of these patients before redo surgery, description of the operation technique and a summary of experiences with the clinical recovery of these patients were provided in this paper.

\section{Results}

Three patients with HD and persistent obstructive symptoms developed a severely dilated non-motile colon, after primary pull-through despite treatment with laxatives, enemas and rectal irrigation. In these three patients, there were no (more) signs of an anastomotic stricture, anal outlet obstruction or residual aganglionosis, which were excluded by contrast enema and biopsy (three patients) and botulinum toxin injections (in one patient). Characteristics of the clinical course before longitudinal resection, details about the procedure and occurrence of complications in each individual patient are provided in Table 1. 
Fig. 1 Illustration of the technique of longitudinal antimesenteric resection

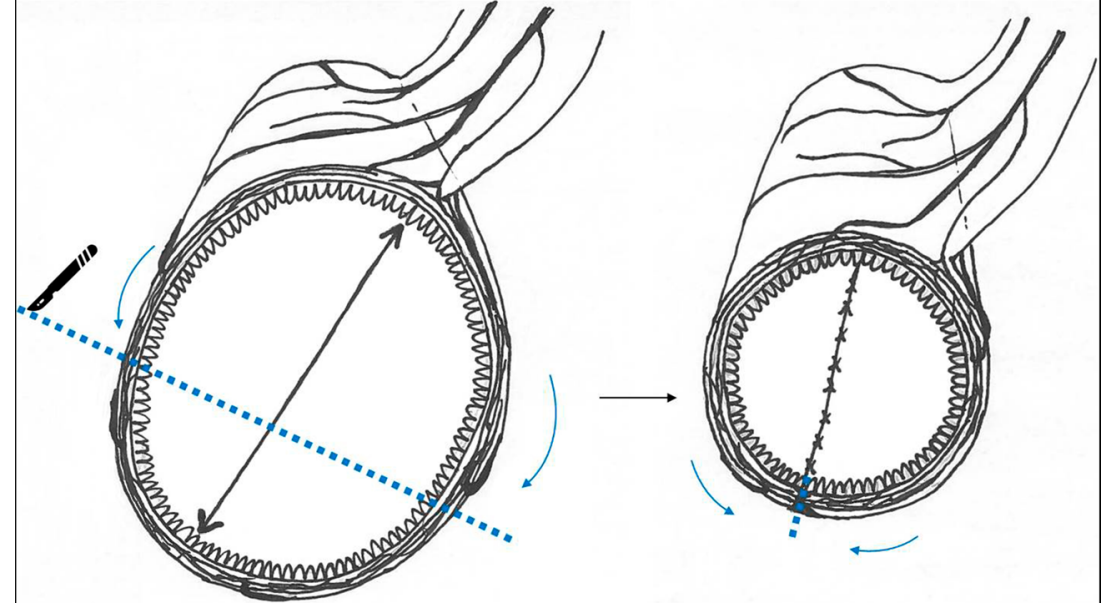

\section{Description of the procedure}

The patients in this series underwent longitudinal antimesenteric resection of the distended colon with a longitudinal anastomosis, instead of complete resection of the dilated segment followed by a redo pull-through, in order to preserve as much bowel (function) and vascularization as possible. Figure 1 illustrates the technique. The key is to resect the antimesenteric side of the circumference over the length of the distended segment. The amount of bowel to resect is dependent of the degree of distension, as the purpose is to recreate normal bowel diameter. A longitudinal anastomosis is created in order to reconnect both ends of the bowel wall, which can either be done by hand-suturing or by stapling. A protective temporary ostomy was created in all three patients.

\section{Clinical outcomes in follow-up}

Our three patients had uneventful recovery after longitudinal resection. There was no mortality and there were no postoperative complications within 30 days. In follow-up, contrast enemas confirmed good peristalsis of the plicated segment without signs of anastomotic leakage or stricture in the three patients after 2-8 weeks after longitudinal resection and the bowel remained of a normal diameter (Fig. 2, Fig. 3 and Fig. 4). Subsequently, in the three patients, the temporary protective ostomy could be closed within 2 months after longitudinal resection. In follow-up after closing the ostomy, the bowel function of all patients had substantially improved compared with before the procedure. All three patients have retained regular bowel movements since longitudinal resection with either low-dose oral laxatives (Macrogolum) (patient A) or occasional preventive rectal irrigation (patient $\mathrm{C}$ ). Only patient B, who initially also had satisfactory clinical outcome with spontaneous bowel movements without laxatives or irrigation, withdrew from follow-up because of psychosocial factors and presented again 1 year later with recurrence of a severely dilated small bowel and an inflamed ileum, for which he underwent resection of the inflamed ileal segment and a second longitudinal resection of the dilated ileum. Since this second longitudinal resection, the patient again has regular bowel movements and uses no laxatives or irrigation. None

Fig. 2 Patient A before (a) and after (b) longitudinal antimesenteric resection
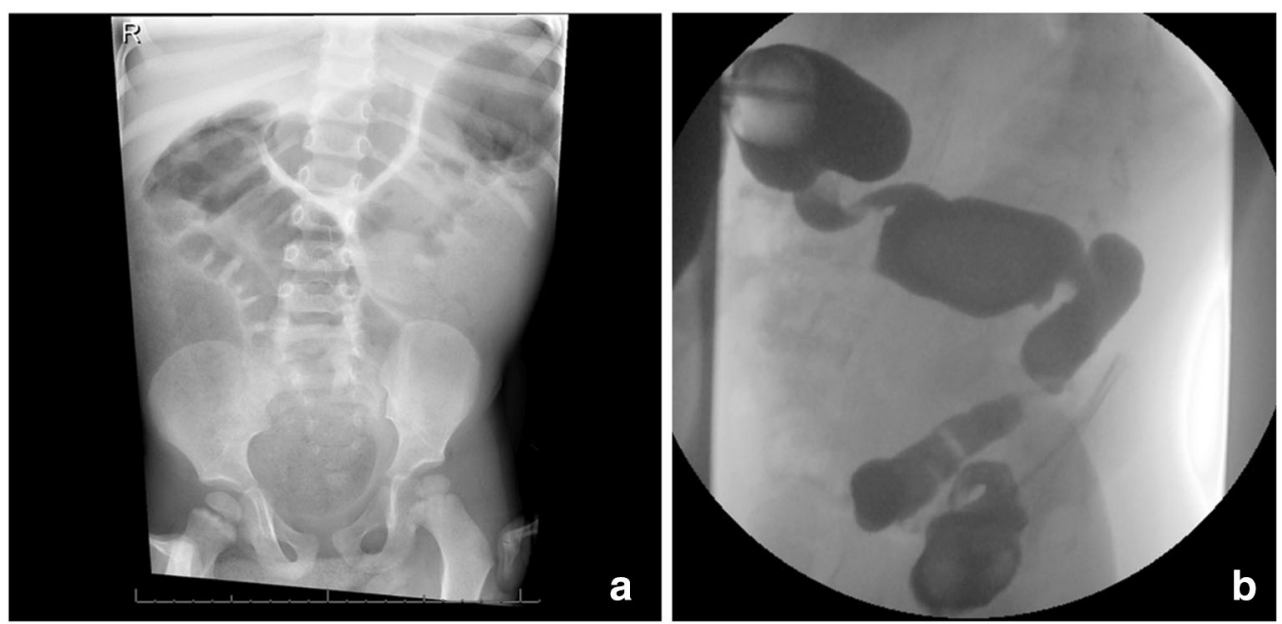
Fig. 3 Patient B before (a) and after (b) longitudinal antimesenteric resection
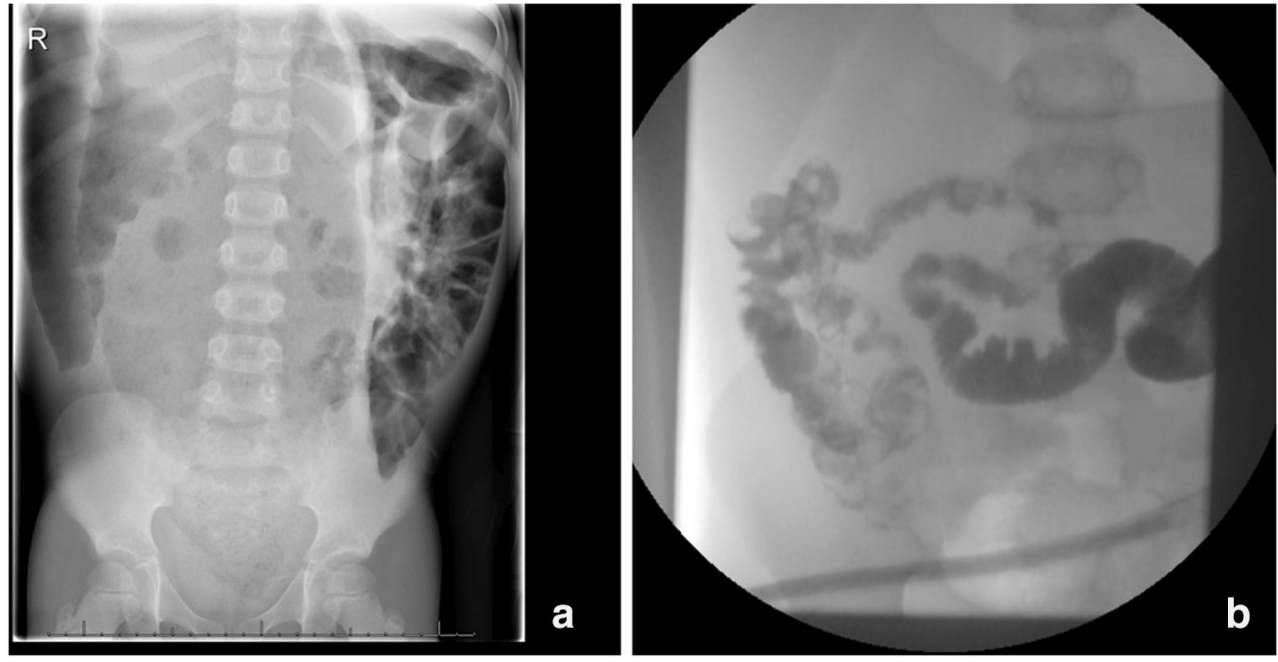

of the patients showed clinical signs of obstruction in the follow-up period after the last longitudinal resection.

\section{Discussion}

Our study shows excellent short to medium term results after longitudinal resection in patients who developed distended bowel and obstructive symptoms after primary surgery because of Hirschsprung disease, with good clinical recovery. This indicates that longitudinal antimesenteric resection might be a safe and effective alternative treatment strategy for Hirschsprung patients with extremely dilated bowel because of persistent obstructive defecation problems after a pull through.

There is currently no consensus on the best surgical procedure for this group of patients [7, 10-13]. Frequently used techniques for secondary surgery include resection of the dilated segment with or without a redo pull-through, myotomy of the sphincter or a permanent colostomy. Disadvantages of re-resection of the dilated segment without a redo pull-through are further omission of bowel length and vascular supply, as well as jeopardizing the distal segment if the original distal anastomosis remains in place. Simultaneous resection of the distal segment as well carries higher risk of future defecation disorders, especially faecal incontinence [14]. Disadvantage of a permanent colostomy is the time-consuming daily care, as well as the risk of stoma-related complications such as skin problems, prolapse and parastomal herniation [15]. A longitudinal resection leads to recovery of normal bowel diameter, thus decreasing bowel wall tension and increasing intraluminal pressure, thereby improving peristalsis and passage of faeces through the bowel. Moreover, this technique offers the benefit of preservation of larger sections of the colon and thus its resorbing function, as well as sustaining optimal vascularization of the gut. This is important as both damage of the vascular arcade and interruption of intramural blood supply may result in bowel necrosis or fibrosis with possible devastating consequences for continence later in life. In this small series, we had no complications of longitudinal antimesenteric resection.
Fig. 4 Patient $\mathrm{C}$ before (a) and after (b) longitudinal antimesenteric resection
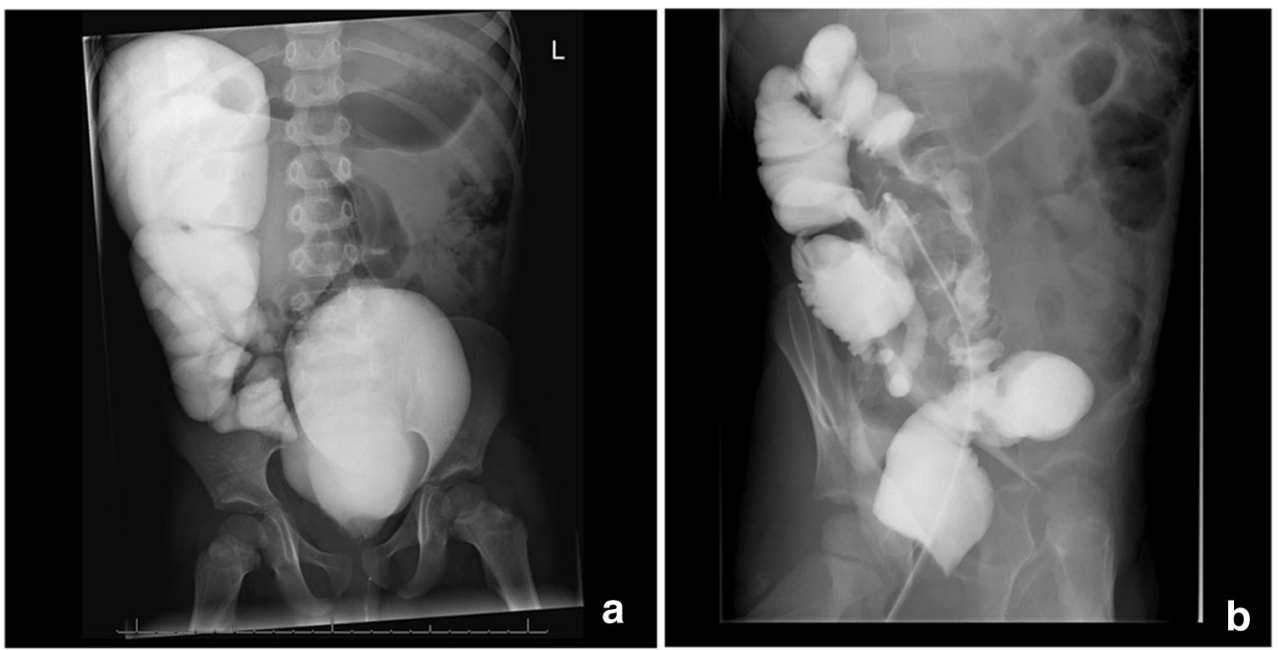
Despite the good results in terms of bowel diameter and clinical improvement in our patients, we still have limited experience with longitudinal antimesenteric resection. This technique is suitable for patients with a permanent severely dilated colon, without any signs of residual aganglionosis or an anastomotic stricture as cause of obstruction. Therefore, this treatment option can only be applied for a small and specific subgroup of patients with HD and obstructive symptoms. We have described our experience with longitudinal resection in three patients, but in the future, more and longer experience with this technique is necessary, to assess if the good results can be confirmed and which patients would benefit most of this technique.

In conclusion, longitudinal antimesenteric resection is a surgical procedure offering multiple benefits for patients with HD with obstructive complaints and distended bowel for whom redo surgery is indicated: the preservation of bowel and vascularization. In this case series, clinical outcomes were good, but further research on outcomes in long-term follow-up and possible complications is necessary before clinical implications can be recommended.

Acknowledgements The authors thank Simon Robben for providing the abdominal X-ray and contras enema images.

Author contributions Heurn LWE and Derikx JPM designed the research; Roorda D, Visschers RGJ and Surridge TJ performed the dataextraction. Roorda D performed a review of relevant literature. Roorda D and Derikx JPM analysed the data. Roorda D, Visschers RGJ, Surridge TJ, van Heurn LWE and Derikx JPM wrote and revised the paper. All authors approved of the final version of the paper.

\section{Compliance with ethical standards}

This retrospective study was approved by the local Institutional Review Board of the Maastricht University Medical Centre and written consent was obtained from all (parents of) individual participants for whom identifying information is included in this article.

Conflict of interest The authors declare that they have no conflict of interest.

Open Access This article is distributed under the terms of the Creative Commons Attribution 4.0 International License (http:// creativecommons.org/licenses/by/4.0/), which permits unrestricted use, distribution, and reproduction in any medium, provided you give appropriate credit to the original author(s) and the source, provide a link to the Creative Commons license, and indicate if changes were made.
2. Wester T, Zetterlind L, Fredin K, Olsen L (2006) Postoperative obstructive symptoms are common after Rehbein's procedure for Hirschsprung's disease. Eur J Pediatr Surg 16(2):100-103

3. Langer JC, Rollins MD, Levitt M et al (2017) Guidelines for the management of postoperative obstructive symptoms in children with Hirschsprung disease. Pediatr Surg Int 33(5):523-526

4. Romo Munoz MI, Martinez de Aragon A, Nunez Cerezo V et al (2018) Risk factors associated with the development of enterocolitis in Hirschsprung's disease. Cir Pediatr 31(1):34-38

5. Gosain A, Frykman PK, Cowles RA et al (2017) Guidelines for the diagnosis and management of Hirschsprung-associated enterocolitis. Pediatr Surg Int 33(5):517-521

6. Han JW, Youn JK, Oh C, Kim HY, Jung SE, Park KW (2018) Why do the patients with Hirschsprung disease get redo pull-through operation? Eur J Pediatr Surg. https://doi.org/10.1055/s-00381667038

7. Ralls MW, Coran AG, Teitelbaum DH (2017) Redo pullthrough for Hirschsprung disease. Pediatr Surg Int 33(4):455-460

8. Ralls MW, Freeman JJ, Rabah R, Coran AG, Ehrlich PF, Hirschl RB, Teitelbaum DH (2014) Redo pullthrough for Hirschsprung disease: a single surgical group's experience. J Pediatr Surg 49(9): 1394-1399

9. Dingemans A, van der Steeg H, Rassouli-Kirchmeier R, Linssen MW, van Rooij I, de Blaauw I (2017) Redo pull-through surgery in Hirschsprung disease: short-term clinical outcome. J Pediatr Surg 52(9):1446-1450

10. Lawal TA, Chatoorgoon K, Collins MH, Coe A, Peña A, Levitt MA (2011) Redo pull-through in Hirschsprung's [corrected] disease for obstructive symptoms due to residual aganglionosis and transition zone bowel. J Pediatr Surg 46(2):342-347

11. Schweizer P, Berger S, Schweizer M, Holschneider AM, Beck O (2007) Repeated pull-through surgery for complicated Hirschsprung's disease-principles derived from clinical experience. J Pediatr Surg 42(3):536-543

12. Sun S, Chen G, Zheng S, Dong K, Xiao X (2017) Usefulness of posterior sagittal anorectoplasty for redo pull-through in complicated and recurrent Hirschsprung disease: experience with a single surgical group. J Pediatr Surg 52(3):458-462

13. Wildhaber BE, Pakarinen M, Rintala RJ, Coran AG, Teitelbaum DH (2004) Posterior myotomy/myectomy for persistent stooling problems in Hirschsprung's disease. J Pediatr Surg 39(6):920 926; discussion 20-6

14. Meinds RJ, van der Steeg AFW, Sloots CEJ, Witvliet MJ, de Blaauw I, van Gemert WG, Trzpis M, Broens PMA (2019) Longterm functional outcomes and quality of life in patients with Hirschsprung's disease. Br J Surg 106(4):499-507

15. van den Hondel D, Sloots C, Meeussen C, Wijnen R (2014) To split or not to split: colostomy complications for anorectal malformations or hirschsprung disease: a single center experience and a systematic review of the literature. Eur J Pediatr Surg 24(1):61-69

Publisher's note Springer Nature remains neutral with regard to jurisdictional claims in published maps and institutional affiliations.

\section{References}

1. Heuckeroth RO (2018) Hirschsprung disease - integrating basic science and clinical medicine to improve outcomes. Nat Rev Gastroenterol Hepatol 15(3):152-167 